\title{
A Review of Novel Wooded-Based Sandwich Composite with Paper Honeycomb Core
}

\author{
Jingxin Hao* and Qiang Wang \\ College of Material Science and Engineering, Central South University of Forestry and Technology, China
}

*Corresponding author: Jingxin Hao, College of Material Science and Engineering,

Central South University of Forestry and Technology, Changsha, Hunan, China.

Received Date: September 01, 2020

Published Date: September 15, 2020

\begin{abstract}
Wood-based sandwich composite with paper honeycomb core, because of its high-strength-to-weight-ratio and renewable, has potential use in civil industry, such as furniture product, interior decoration and interior wall. However, the traditional hexagonal honeycomb structure don't used as loading components in the product because of its weak mechanical properties. Therefore, three types of novel structures of Taiji honeycomb, traditional honeycomb fortified by wood strip, and corrugated honeycomb are introduced in the paper, which provides the currents situation of innovation in the wood-based sandwich composite with soft core.
\end{abstract}

Keywords: Wood-based composite; Honeycomb; Failure mode

\section{Introduction}

Honeycomb is cellular structure which has high strength-toweight ratio in the transverse direction. Therefore, those structures has been applied as core layer of sandwich panel used in space and marine field since last century, nowadays has spread to civil area. The common materials used for honeycomb are metal, plastic or paper.

Paper honeycomb, as one of green materials, has been widely used in furniture and package products. But little was designed for loading bearing components because of lack of enough strength. The transverse compression strength was only 0.1-0.2Mpa for paper honeycomb with cell size of $8 \mathrm{~mm}$. The strength can be reinforced by reducing cell size of honeycomb or increasing cell wall thickness, but with increasing rapidly density of structure. Recently the new concepts for honeycomb with high strength were proposed by optimizing the morphology of cell unit or by constructing combination between paper and wood. The objective of the paper is to exhibit some novel cellular structures of honeycomb and its fabrication process.

\section{New Structures of Honeycomb Core}

\section{Taiji honeycomb structure}

As cell size is less than $6 \mathrm{~mm}$, it was very difficult to stretch the honeycomb to the cellular structure with regular hexagonal, which means more raw materials needs to be used with same filled volume in the core layer. Therefore, the Taiji honeycomb was obtained by adding a curved paper inside of every cell unit, thus three layers of laminated paper wall in the interface of gluing area was formed with enhancing dramatically to stability of thin wall of cellular structure [1]. Hao et al. gave the results that compression strength and modulus of composite with Taiji honeycomb is 2.45 times and 2.7 times respectively than that of traditional hexagonal honeycomb with same cellular size (Figure 1). 


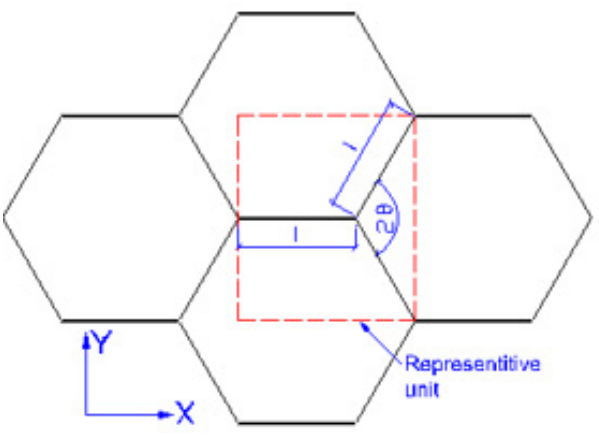

(a)

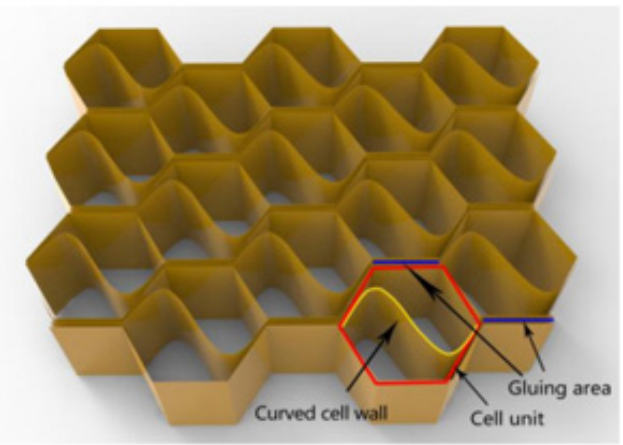

(b)

Figure 1: The idealized structure of honeycomb core: (a) Traditional hexagonal honeycomb, (b) Taiji honeycomb [1].

\section{Paper honeycomb fortified by wood-based strip}

Another method to enhance the strength of paper-based honeycomb is to put wood-based strip on the gluing interface between cell unit. The experiments exhibited the compression and bending strength of reinforced honeycomb with cell size of $15 \mathrm{~mm}$ and plywood strip in thickness of $2.7 \mathrm{~mm}$ are $1.2 \mathrm{Mpa}$ and $2.7 \mathrm{Mpa}$ respectively [2]. These type materials has potential use for book self, door and interior walls etc. (Figure 2).

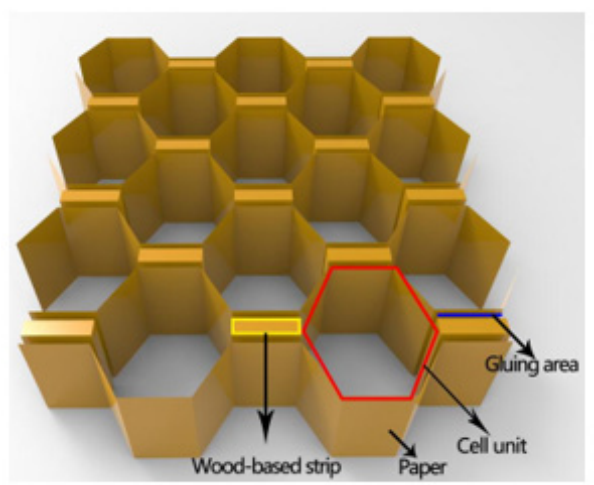

Figure 2: The paper honeycomb structure fortified by wood-based strip.

\section{Corrugated honeycomb structure}

Stacking corrugated strip one by one, another type of honeycomb structure is proposed as depicted in Figure 3.Corrugated honeycomb has stronger bending rigidity and compression properties than that of traditional hexagonal one despite the relative higher density. It was also shown by Chen et al. [3] that sandwich composite with corrugated core has lower flexural creep rate that that of traditional hexagonal honeycomb (Figure 3).

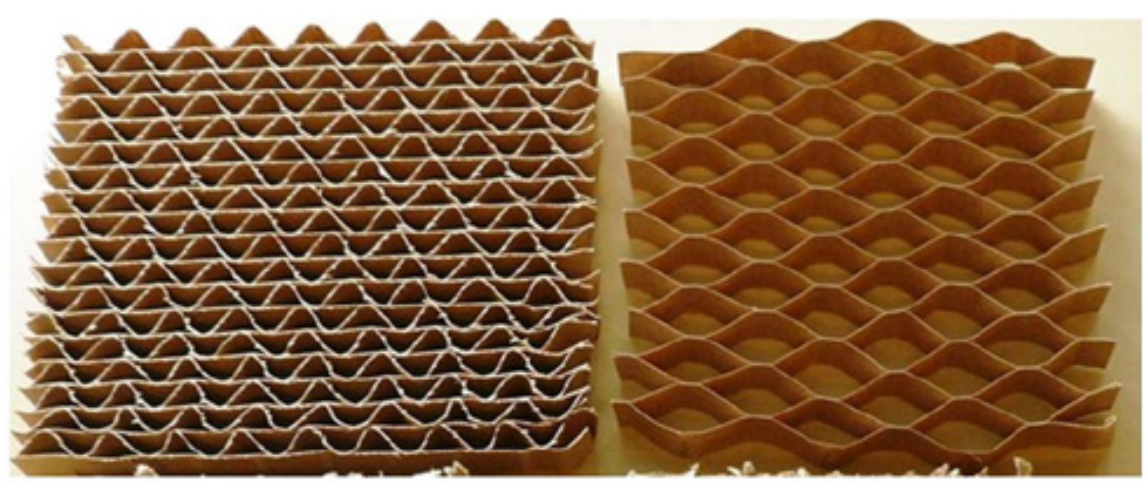

Figure 3: The photograph comparison of two different honeycomb: (a) corrugated honeycomb; (b) traditional hexagonal honeycomb [3]. 
Failure Mode of Wood-Based Sandwich Composite with Paper Honeycomb Core

Sandwich structure failure can be caused by skin or weak core, or together. It should be noted that skin mainly take the tensile stress and core is responsible for the shear resistance. As for the wood based sandwich composite with paper honeycomb core, the dominant failure mode under bending are core shear or indentation because of the stronger wood surface while the cell bucking of honeycomb core decides the compression strength of whole sandwich structure [4-6] (Figure 4).

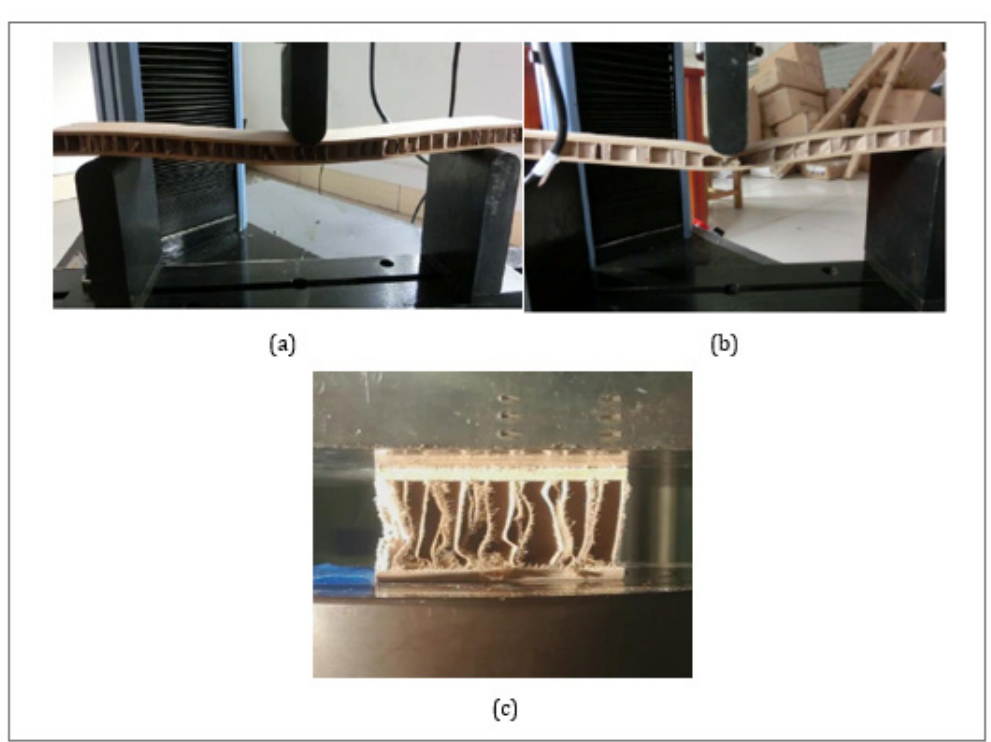

Figure 4: The typical failure mode of wood-based sandwich composite with paper honeycomb core: (a) core shear under three-point bending; (b) surface indentation under three-point bending; (c) core cell bucking under compression [4-6].

\section{Conclusion}

As for wood-based sandwich composite with soft core such as paper honeycomb etc., the properties of core layer decide the loading level of entire structure. Therefore, innovation of honeycomb was an effective method to fortify the strength of composite. Taiji honeycomb and corrugated cellular structure has a potential use in the common loading product such as furniture, door. while the honeycomb reinforced by wood strip can be used in heavy loading level such as interior wall.

\section{Acknowledgement}

None.

\section{Conflict of Interest}

No conflict of interest.

\section{References}

1. Hao JX, Wu XF, Oporto G, Wang JX, Dahle G, et al. (2018) Deformation and failure behavior of wooden sandwich composite with Taiji honeycomb core under three-point bending. Materials 11(11): 2325.
2. Si LL (2012) Study on the mechanical properties of wood material enhanced paper honeycomb core composite boards. Forestry Machinery \& Woodworking Equipment 40: 25-28.

3. Chen Z, Yan N, Deng J, Smith G (2011) Flexural creep behavior of sandwich panels containing Kraft paper honeycomb core and wood composite skins. Materials Science and Engineering A 528(16-17): 5621-5626.

4. Hao JX, Xu L, Wu XF, Li Xj (2020) Analysis and modeling of the dowel connection in wood $\mathrm{T}$ type joint for optimal performance. Composite Structure 253: 112754

5. Hao JX, Wu XF, Oporto G, Liu WJ, Wang JX (2020) Structural analysis and strength-to-weight optimization of wood-based sandwich composite with honeycomb core under three-point flexural test. European Journal of Wood and Wood Product.

6. Hao JX, Wu XF, Oporto G, Wang JX, Dahle G (2020) Compression Properties and Its Prediction of Wood-Based Sandwich Panels with a Novel Taiji Honeycomb Core. Forests 11(886): 1-13. 